\title{
Clinical and microbiological characterization of Clostridium difficile infection in Romania (2013-2014); a hospital-based study
}

\author{
Gabriel Adrian Popescu ${ }^{1,2^{*}}$, Roxana Serban ${ }^{3}$, Adriana Pistol $^{3}$, Andreea Niculcea $^{3}$, Andreea Preda ${ }^{3}$, Daniela Lemeni ${ }^{4}$, \\ Ioana Macovei ${ }^{4}$, Monica Popoiu², Cristina Țenea ${ }^{2}$, Daniela Tălăpan², Dragoş Florea ${ }^{1,2}$, Alexandru Rafila1,2 \\ From The 10th Edition of the Scientific Days of the National Institute for Infectious Diseases "Prof Dr Matei \\ Bals" \\ Bucharest, Romania. 15-17 October 2014
}

\section{Background}

Since 2011 Clostridium difficile infection (CDI) has been an emerging nosocomial problem in Romanian hospitals, due to its growing incidence and severity. Objectives: To describe risk factors and clinical outcome for CDI cases, and strains characterization.

\section{Methods}

We collected data for all 398 confirmed or probable cases of CDI admitted during 15 November 2013-28 February 2014 in 11 hospitals: 5 from Bucharest, and 7 from Cluj, Iaşi, Timişoara, Târgu Mureş and Braşov. PCR ribotyping was performed at Cantacuzino Institute and E-test (for moxifloxacin and metronidazole) and binary toxin gene identification (PCR) were performed at Matei Balş Institute. The hospitals sent a maximum 20 feces samples for each test.

\section{Results}

Mean age was 63.4 years (range 1-94 years), and sex ratio $\mathrm{F}: \mathrm{M}=1.08: 1$. For 40 patients, CDI were communityacquired, $12.5 \% \mathrm{CI} 95 \%$ (9.3\%-16.6\%), if indeterminate origin cases were excluded; 12 of 13 strains tested from these patients were ribotype 027 and/or binary toxin positive. A post-antibiotic CDI were documented in 346/385 analyzable cases, $89.9 \%$ CI95\% (86.5\%-92.5\%); $53.6 \%$ of them received medication from at least two different antibiotic groups. The most utilized antibiotics were cephalosporins and quinolones. In $13.1 \%$ cases with known history, the

\footnotetext{
* Correspondence: gabrielp9@yahoo.com

${ }^{1}$ Carol Davila University of Medicine and Pharmacy, Bucharest, Romania
}

Full list of author information is available at the end of the article
CDI episode was a recurrent one CI95\% (10.1\%-17\%); binary toxin was retrieved in all six tested strains from recurrent CDI. A number of 45 episodes were considered severe CDI (25 deaths, 7 intensive care required, 6 colectomies, 7 patients discharged with worsened condition), 12.1\% from 371 episodes with identified outcome CI95\% (9.2\%-15.8\%). From 155 tested strains, 122 belonged to 027 ribotype and/or were binary toxin positive, $78.7 \%$ CI95\% (71.6\%-84.4\%); the remaining 33 strains belonged to ribotypes $002(\mathrm{n}=4), 014(\mathrm{n}=2), 018(\mathrm{n}=2), 087(\mathrm{n}=2)$, one isolate each 001, 011, 012, 017, 020, 106 ribotypes and 17 strains were binary toxin negatives. The 027 ribotype and/or binary toxin presence were prevalent in all hospitals, ranging from $69.7 \%$ to $100 \%$. In 62 of 84 tested isolates, the MIC for moxifloxacin was greater than $2 \mathrm{mg} / \mathrm{L}$, the epidemiological cut-off value, more frequent in ribotype 027 or binary toxin positive strains, $R R=2.02(1.27 ; 3.22)$, $\mathrm{p}<0.0001$.

\section{Conclusion}

The severe CDI episodes were relatively frequent in our study. The main risk factor for CDI was the previous antibiotic treatment, especially with cephalosporins and quinolones. The wide circulation of 027 ribotype could explain the persistence of hospital outbreaks of CDI and the increase of community-acquired CDI episodes. No discrepancies were noticed among participant hospitals.

\footnotetext{
Authors' details

${ }^{1}$ Carol Davila University of Medicine and Pharmacy, Bucharest, Romania. ${ }^{2}$ National Institute for Infectious Diseases "Prof. Dr. Matei Balş", Bucharest, Romania. ${ }^{3}$ National Institute of Public Health, Bucharest, Romania.
} 
${ }^{4}$ Cantacuzino National Institute for Research and Development for Microbiology and Immunology, Bucharest, Romania.

Published: 15 October 2014

doi:10.1186/1471-2334-14-S7-024

Cite this article as: Popescu et al:: Clinical and microbiological

characterization of Clostridium difficile infection in Romania (2013-2014);

a hospital-based study. BMC Infectious Diseases 2014 14(Suppl 7):O24.

Submit your next manuscript to BioMed Central and take full advantage of:

- Convenient online submission

- Thorough peer review

- No space constraints or color figure charges

- Immediate publication on acceptance

- Inclusion in PubMed, CAS, Scopus and Google Scholar

- Research which is freely available for redistribution

Submit your manuscript at www.biomedcentral.com/submit

() BioMed Central 